A Comparison of Platinum Thermometers of different degrees of Purity

This content has been downloaded from IOPscience. Please scroll down to see the full text. 1899 Proc. Phys. Soc. London 17341

(http://iopscience.iop.org/1478-7814/17/1/326)

View the table of contents for this issue, or go to the journal homepage for more

Download details:

IP Address: 130.126.162.126

This content was downloaded on 07/09/2015 at 00:46

Please note that terms and conditions apply. 
XXV. A Comparison of Platinum Thermometers of different degrees of Purity. By H. M. TorY, M.A., Mathematical Lecturer at Mc Gill College, Montreal*.

1. THIS investigation was undertaken at the suggestion of Professor Callendar with a view to determining the probable order of accuracy in the determination of high temperatures attainable by the use of ordinary commercial specimens of platinum wire. It was also desired to observe the effect of large variations in the purity of the wire, in order to be able to estimate the probable effect of such small impurities as were likely to occur in pure wires specially selected for pyrometry. Five wires in all were compared over the range $400^{\circ}$ to $1000^{\circ} \mathrm{C}$. The fundamental coefficients of the wires (which may be taken as an indication of the purity) varied from $\cdot 003892$ to $\cdot 002340$, i.e. by 40 per cent. of the maximum value. It was found, however, that the extrome variations of the temperatures observed, when calculated on the platinum scale by the formula

$$
p t=100\left(\mathrm{R}-\mathrm{R}^{\circ}\right) /\left(\mathrm{R}^{\prime}-\mathrm{R}^{\circ}\right), . . \quad .
$$

in which the letters $R, R^{\prime}$, and $R^{\circ}$ stand for the observed resistance at the temperatures $p t, 100^{\circ}$, and $0^{\circ} \mathrm{C}$. respectively, did not in any case exceed $9^{\circ} \mathrm{C}$. at $1000^{\circ} \mathrm{C}$, or were less than one per cent. on the interval at any point of the range of observation, in spite of the large differences in the samples.

When the temperatures were reduced by means of the difference-formula

$$
t-p t=d t(t-100) / 10,000, \quad . \quad . \quad . \quad .
$$

although the agreement was found to be exceedingly close at temperatures up to $500^{\circ} \mathrm{C}$. (if the value of the difference-coefficient $d$ was calculated by assuming the boilingpoint of sulphur (S.B.P.) to be $444^{\circ} .53$ C., by the method proposed by Callendar and Griffiths), the discrepancies at $1000^{\circ}$ were still of the order of $5^{\circ}$ or $10^{\circ} \mathrm{C}$. We untust conclule that this method of reduction by reference to the 
S.B.P. will not give results of the highest accuracy if applied to impure wires at $1000^{\circ} \mathrm{C}$. This point has also been illustrated by Callendar (Phil. Mag. Feb. 1899). It was found, however, that very fuir agreement could be obtained at bigh temperatures by using the freezing-point of silver (AgF.P.) as a secondary fixed point instead of the S.B.P. in the calculation of the difference-coefficient. For two of the wires the simple method of reduction employed by Heycock and Neville (Journ. Chem. Soc. Feb. 1895, and Phil. Mag. Feb. 1899, p. 200) gave results agreeing with the standard wire almost within the limits of error of observation. but did not apply so well in the case of the most impure specimens. It was observed, however, that the differences of the platinum temperatures for all the wires could be very closely represented between the limits of observation by linear formulx. If the observed values of $p t$ for each wire were first reduced to the standard $p t$ in each case by the linear relation, and then corrected by the same differenceformula as the standard wire, very consistent results were obtained from all the wires. This method would not be applicable below $400^{\circ} \mathrm{C}$, but it might prove a suitable type of formula for purposes of extrapolation, in case it was necessary to employ impure wires.

It is probable that the platinum wires used in this investigation were free from contamination with baser metals outside the platinum group. Under proper conditions they all showed great constancy of zero, and the variation of the differencecoefficients (from 1.50 to 1.67 ) was comparatively small. By contamination with baser or more volatile metals, it is possible to get much larger variations in the values of $p t$ and $d$; but such pyrometers will not show constant results until the volatile constituents have been burnt out. Special attention was given to the effects of annealing which may produce changes of zero of the order of one degree after the first exposure to a temperature of $1000^{\circ} \mathrm{C}$. With this exception, no changes of zero of any importance were observed, as the temperatures employed never exceeded $1000^{\circ} \mathrm{C}$.

2. Methods and Apparatus.-The method of comparison adopted was that described by Callendar (Phil. Trans. $\Lambda, 1887$, 
p. 161), in which the wires to be compared are wound side by side in the same tube, so as to be always at the same mean temperature. This method appears to be more accurate than the method of indirect comparison of pyrometers in separate tubes. Observations were taken at steady temperatures only, in a well-stirred bath of melted tin. The apparatus was arranged so that the readings of the two pyrometers were almost simultaneous. Each wire was directly compared with the pure standard wire; and in addition a specimen of the standard was drawn down to half section, and compared with the original wire. The agreement was found to be exact throughout the scale, as was to be expected with so pure a wire. The wires were wound on mica strips with platinum leads insulated in the usual manner. Each double pyrometer, when completed, had six leads, two each for the pyrometer coils, and two compensating leads. The resistance-box used was one of the type described by Callendar (Phil. May. July 1891) with coils on the binary scale, standardized in the usual manner. The contact surfaces of the screw-nuts used for short-circuiting the coils were kept clean, and the contacts frequently tested. The galvanometer used was one specially designed by Prof. Callendar (Phil. Mag. Feb. 1892) for resistance pyrometer work, with an astatic-needle system in which the control is due to the passage of a current through a pair of coils, marked "Field" in fig. 1, at right angles to the position of the galvanometer-coils. The current which effects the control is proportional to that used in measuring the resistance, and bence the deflexion due to any given difference of resistance is constant, no matter what the current may be. It was found, for example, that the deflexion for a difference of resistance of one unit of the bridge, was exactly the same whether a two-volt or four-volt battery was used.

In order to secure a proper sensitiveness of the needle, the field or control coils were shunted with a small resistance marked $\mathrm{Sh}$, which was adjusted so that a change of resistance of one bridge-unit produced a deflexion equal to 10 divisions of the galvanometer-scale. By this means, the deflexions could be read to $1 / 100$ of a degree, which was sufficient for the purpose. 
3. Resistance Measurements.-The ratio-coils of the bridge were connected permanently in the galvanometer-case, and had a fixed resistance of about 10 ohms each, being made exactly equal. The standard or balancing coil $M I$, against

Fig. 1.

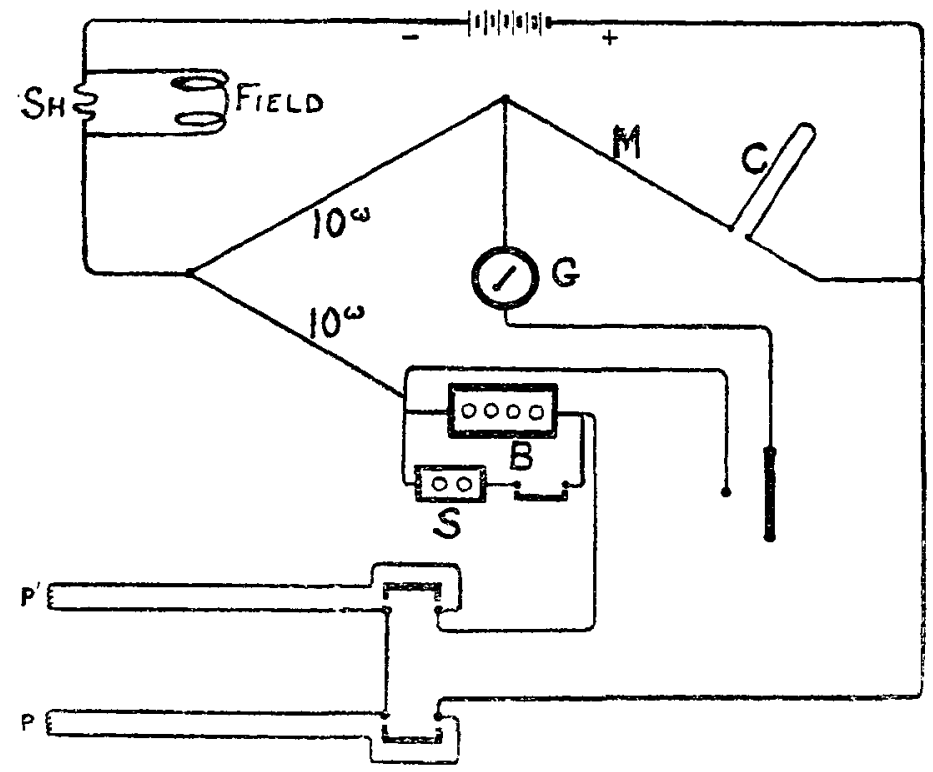

which the resistances of the pyrometer and box were balanced, was also fixed permanently in connexion with the galvanometer, but in such a way that it could be kept in a test-tube of oil, and its temperature taken after each observation. The compensating leads ( $Y$ were in series with this coil. The adjustable resistance-box $B$ was inserted in the same arm as the pyrometer, and readings were taken by the method of substitution, so as to keep the resistance in circuit constant.

Before the pyrometer was put in the circuit, the balancingcoil $M$ was adjusted exactly equal to the total resistance of the box $\mathrm{B}$ at $20^{\circ} \mathrm{C}$, , so that when the pyrometer was inserted in the same arm as the box its resistance could be at once determined by reading the resistances of the box that were short-circuited, and taking the deflexion of the galvanometer. In addition to the usual eoils in the box, namely, 640,320 , 
$160,80,40,20,10$ units, two others were added, of 5 and 2 units respectively; so that deflexions of the galvanometer greater than 20 scale-divisions were never required to be taken. Ordinarily it is not necessary to adjust the balancingcoil $M$ equal to the resistance of the box, as only the differences $R-R^{\circ}$ and $R^{\prime}-R^{\circ}$ are required. It was convenient, however, in order to get the temperature-coefficient of the wire used. The temperature-coefficient of the platinumsilver box coils was determined to be $\cdot 000330$ per degree, and that of the manganin balancing-coil $M$ to be 000045 . All the observations were corrected for both box and coil.

The resistances of the pyrometers used for comparison, owing to the large differences in the temperature-coefficients of the wires, differed considerably, excepting at the points where they were calculated to agree. The fundamental interval, $R^{\prime}-R^{\circ}$, was usually calculated for one pyrometer to be 100 approximately, and the other to have a noarly equal resistance at $500^{\circ}$, the temperature-coefficients being roughly determined before the pyrometers were made up. The result of this difference of resistance was, that it was found exceedingly difficult to take readings of the pyrometers in the usual winy so quickly as to be sure that the temperature was constant to $1 / 10$ of a degree during the process. The pyrometers were first connected in series, so that one could be immediately short-circuited and the other read after adjusting the resistance in the box. The time required to take a reading in this way, on account of the swing of the needle of the galvanometer, was about three minutes.

4. Shunt method of Comparison. - In order to get over this difficulty and secure simultaneous readings, the following method was adopted. The two pyrometers $P$ and $P_{1}$ were connected in series with the resistance-box $B$, through a merculy-cup switch, so that by rocking the top of the switch they could be short-circuited one after the other, by means of thick copper wires attached to the rocker. Connected with the same switch there was an arrangement such that when $P_{1}$ was short-circuited and $P$ was to be measured, the box $B$ was shunted by meuns of a mercury connexion. The shunt-box $S$ was then adjusted so that the deflexion of the galvanometer for $P_{1}$ with $B$ unshunted was exactly the same as that of $P$ 
with the shnnt $S$ in parallel with $B$. The shunt $S$ was a standard resistance-box in olums with an attachment for reading to tenths. As the shunt $\mathrm{S}$ was usually large compared with $B$, it was not necessary to know $S$ nearer than $1 / 10$ of an ohm, while the change of resistance, due to the change of temperature of the box, was negligible. Further, an arrangement was made on the same switch for opening and closing the galvanometer circuit, so that the galvanometer was opened first and closed last on rocking the switch. The result was, since, as before stated, the units of the box were so arranged that a deflexion of 20 scale-divisions was the largest necessary, that with a little practice the switch could be rocked and the deflexions of the two pyrometers read almost simultaneously, the needle of the galvanometer not swinging more than a couple of scale-divisions. The readings could be easily taken within five seconds of each other, and verified again and again without the slightest difficulty, as the temperature slowly changed. The use of the shunt, while it diminished the difficulty of taking observations, somewhat increased the labour of calculation. If $\left(\mathrm{P}_{2}-\mathrm{P}_{1}\right)$ be the difference of resistance of the two pyromoters for any temperature, and $\mathrm{B}$ the resistance in the box which with the pyrometer $P_{1}$ balances the standard coil $M$, and if $S$ be the shunt to $B$ for the second pyrometer $P_{2}$, then

whence

$$
\mathrm{M}=\mathrm{P}_{1}+\mathrm{B}=\mathrm{P}_{2}+\mathrm{BS} /(\mathrm{B}+\mathrm{S}),
$$

$$
\mathrm{P}_{2}-\mathrm{P}_{1}=\mathrm{B}^{2} /(\mathrm{B}+\mathrm{S}), \text {. . . . . }
$$

assuming the deflexions of the two pyrometers to be the same. The factor for reducing the units of the shunt-box (ohms) to units of the pyrometer-box was determined from equation (3) by observations taken at $0^{\circ}, 100^{\circ}$, and $444^{\circ} .5$ (the boiling-point of sulphur) first with the two pyrometers separately using the box B only, and then simultaneously, using the shunt with the second pyrometer.

5. Wethod of Heating.-In order to get an accurate comparison, only steady temperatures were used. For this purpose, the pyrometers, enclosed in a porcelain tube, were heated in an iron pot of molten tin, and the gas-supply regulated by means of a constant-pressure gas-regulator. The gas also flowed through a graduated gas-supply regulator. 
so that, with a little patience, almost any temperature between $400^{\circ}$ and $1000^{\circ} \mathrm{C}$. could be obtained. The furnace used was one whose maximum was $1000^{\circ}$, so that the observations were not taken beyond that point. The molten tin was continuously stirred by means of an air-engine and stirrer. It was found necessary to make the stirrer of fire-clay or tool-steel. When iron was used, the action of the tin at its surface, on the iron, soon rendered it useless. To prevent oxidation of the tin, which took place very rapidly when the surface was exposed, and as a result soon filled the pot with tin oxide in a semiviscous condition, various expedients were used. The one which succeeded best was to keep the surface covered with a stratum, half a centimetre thick, of ground arc-light carbon.

The greatest difficulty experienced was due to the action of the tin on the porcelain tubes. They would not stand repeated heatings in the tin bath, but became very rotten. Several of the observations were spoiled by the tubes breaking at the moment of removing them from the molten tin. It was sometimes difficult at first to remove the pyrometer-tubes, because of the oxidized tin on the surface. After the difficulty of oxidation was overcome, less trouble was experienced, but the tubes were never used more than two or three times without becoming so affected at the junction with the surface of the tin, as to $m$ rke it undesirable to use them again. In taking the melting-point of silver, the tubes which had been previously used for only one set of observations in tin, generally broke when removing them from the melted silver, though the greatest care was exercised.

b. Results of Observations.-Four different samples of ordinary platinum wire were compared with a very pure specimen in general use in the laboratory as a standurd, between $400^{\circ} \mathrm{C}$. and $1000^{\circ} \mathrm{C}$., the two extremes of the furnace used. The temperature-coefficient of the standard wire was found to be slightly different in different pyrometers. These variations were due doubtless to the lack of absolute uniformity in the wire, but were not sufficiently large to affect the readings of temperatures at $1000^{c}$ by more than $1 / 10$ of a degree. The difference-coefficient $d$ of each wire in the formula (2) was calculated from an observation of the boiling-point of sulphur in the usual way. 
The accompanying curves (fig. 2) show graphically the relations between the various wires, plotted with the platinum temperatures of the standard wire as abscissa and for ordinates, the differences $\mathrm{P} t^{\prime}-\mathrm{P} t^{\circ}$, the difference-curve belonging to each wire being denoted by the value of its $d$. It will be seen that the difference-curves are all nearly straight, between the limits of observation. It follows that a linear relation, involving only two unknown quantities, will express the relation of any one of them to the standard, thus :-

$$
p t-p t^{\prime}=a p t+b,
$$

which may be written, if $a$ is small,

$$
p t=p t^{\prime}+a p t^{\prime}+b \text {. }
$$

By abserving therefore the differences between the platinum temperatures of the wires for two points, such as the S.B.P. and the Ag F.P., the constants in formula (4) can be found for each wire.

\section{Tabile I.}

Values of Constants $a$ and $b$ in the Linear Formula (4), for

\begin{tabular}{|c|c|c|c|c|}
\hline $\begin{array}{l}\text { No. of } \\
\text { Wire. }\end{array}$ & $\begin{array}{l}\text { Difference- } \\
\text { Coefficient. }\end{array}$ & $\begin{array}{c}\text { Fundamental } \\
\text { Coeffcient. }\end{array}$ & $\begin{array}{c}\text { Coefflcient } \\
\text { a. }\end{array}$ & $\begin{array}{c}\text { Coefficient } \\
b .\end{array}$ \\
\hline $1 \ldots$. & 1.595 & .003164 & +0103 & $-3 \cdot 14$ \\
\hline 2 & 1.670 & $.00: 2689$ & $+.112+$ & -205 \\
\hline 3 & 1845 & 003216 & $+\cdot 0142$ & -3.80 \\
\hline 4 & 1.530 & .002340 & -0106 & +573 \\
\hline
\end{tabular}
each of the Impure Wires as compared with the Standard.

Since the differences are so small between the different wires, the platinum temperatures observed with each wire can be easily reduced to the scale of the standard wire by the linear formula (4), and then corrected by the standard difference-curve to the scale of the gas-thermometer. The results thus obtained wrould agree within the limits of the present series of observations with the Standard Scale recently 


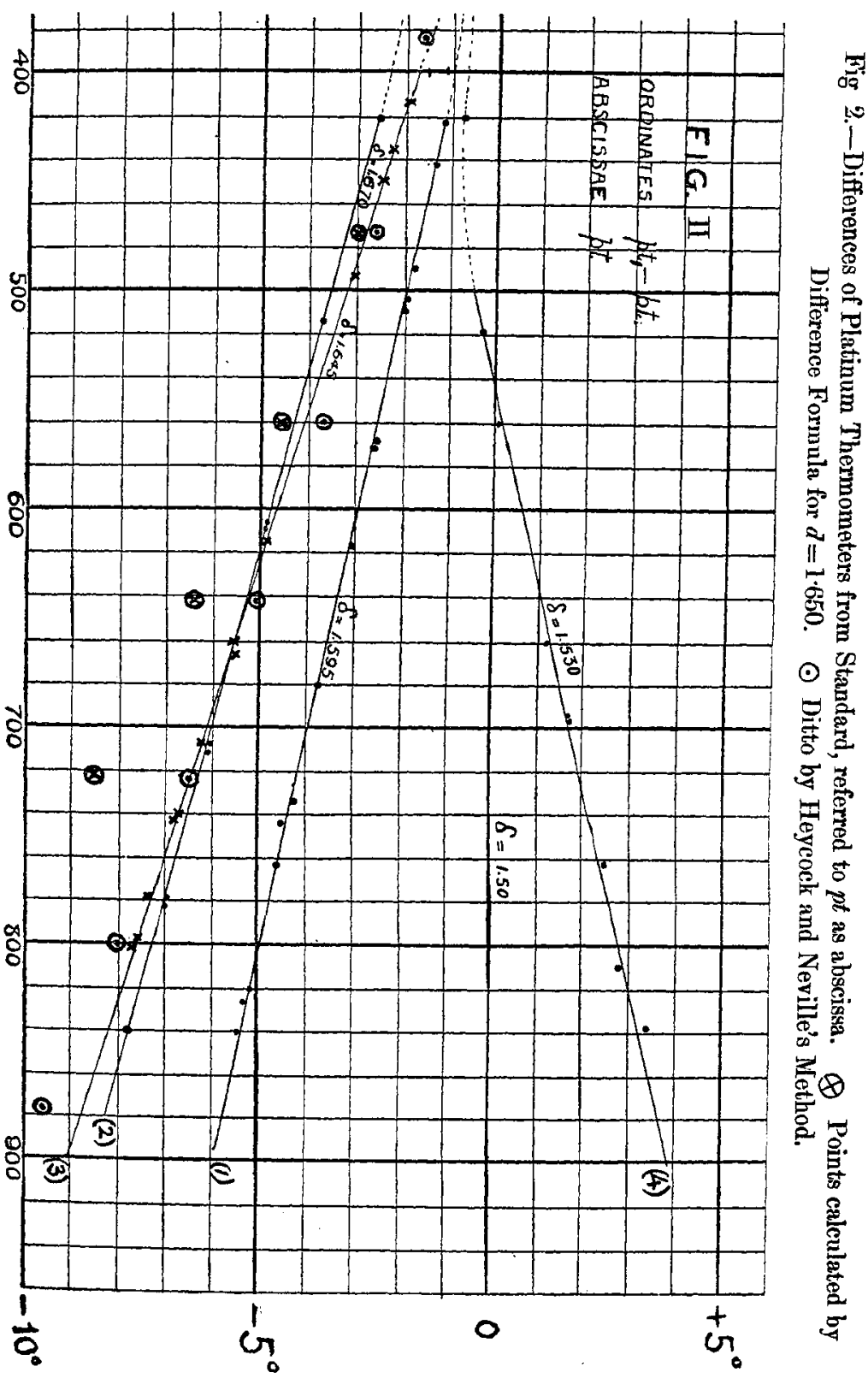


proposed by Callendar (Phil. Mag. Dec. 1899), which is based on the application of the difference-formula (2) to the pure standard wire. In this paper, it is pointed out that in all probahility the value there given for the melting-point of silver, viz. $960^{\circ} \mathrm{C}$, is correct to within $1^{\circ}$ or $2^{\circ}$, and it is suggested that a standard platinum wire be adopted, any other wire being referred to it by determining the melting-point of silver or gold, and the boiling-point of sulphur. To the evidence there adduced might be added the redetermination of the melting-points of gold and silver, by M. Berthelot, who gives the two points as $962^{\circ} \mathrm{C}$. and $1064^{\circ} \mathrm{C}$. It seems to be a reasonable conclusion, therefore, that from $0^{\circ}$ up to the melting-point of gold, $1060^{\circ}$, at least, a practical thermometric scule could be established, which would at no point differ from the gas-thermometer scale by more than $2^{\circ}$ or $3^{\circ}$. It would follow that all observers working with platinum pyrometers could, in a most certain and ready manner, compare their results. The standard sample would thus be defined as a wire with a definite sulphur boiling-point, and a definite silver melting-point. In fact a number of definite points could be defined up the scale, any two of which could be used.

I have not yet carefully studied the difference below $400^{\circ}$ or above $1000^{\circ}$, but hope to do so in the near future. It would appear, however, from results obtained, that the linear difference-curve commences to bend below $400^{\circ}$, meeting the reference line at $100^{\circ} \mathrm{C}$. Such a process of reduction is hardly necessary, however, below $500^{\circ} \mathrm{C}$, as in any good specimen of platinum wire the temperatures can be reduced directly by the difference-formula, using the value of $d$ determined from the S.B.P.

7. Variation of Temperature-Coefficients.-Since the differences between the platinum temperatures of two wires depend on the rate of change of the temperature-coefficients of the wires, the following table may not be uninteresting:- 
TABLE II.

Values of Temperature-Coefficients over Different Ranges.

\begin{tabular}{|c|c|c|c|c|c|c|c|}
\hline $\begin{array}{l}\text { No. of } \\
\text { Wire. }\end{array}$ & \multicolumn{2}{|c|}{$\begin{array}{l}\text { Difference } \\
\text { Cuefficient. }\end{array}$} & $\begin{array}{l}\text { Funda- } \\
\text { mental } \\
\text { Coeffleient, }\end{array}$ & $\begin{array}{l}\text { Coefficient } \\
0^{\circ}-445^{\circ}\end{array}$ & $\begin{array}{l}\text { Per- } \\
\text { cent. } \\
\text { of } c .\end{array}$ & $\begin{array}{c}\text { Coeff- } \\
\text { cient } \\
0^{\circ}-960^{\circ}\end{array}$ & $\begin{array}{l}\text { Per. } \\
\text { cent. } \\
\text { of } c .\end{array}$ \\
\hline 1 & $\begin{array}{l}\text { S.B.P. } \\
1.595\end{array}$ & $\begin{array}{c}\text { AgF.P. } \\
1.561\end{array}$ & .003164 & $\cdot 002991$ & $94 \cdot 6$ & .002739 & $86 \cdot 6$ \\
\hline 2 & 1.670 & $1 \cdot 592$ & .002689 & $\cdot 002533$ & $94 \cdot 7$ & 002322 & $86 \cdot 4$ \\
\hline 3 & 1.645 & $1 \cdot 600$ & 003216 & $\cdot 003033$ & 94.3 & 002775 & $86 \cdot 3$ \\
\hline 4 & 1.530 & $1 \cdot 461$ & .002340 & $\cdot 002215$ & $94 \cdot 6$ & 002047 & $87 \cdot 4$ \\
\hline Standard & 1.500 & $1 \cdot 500$ & $\cdot 003892$ & $\cdot 003692$ & $94 \cdot 8$ & .003391 & $87 \cdot 0$ \\
\hline
\end{tabular}

It will be observed that the percentage diminution of the coefficient of each of the wires is nearly the same over the range $0^{\circ}$ to $960^{\circ}$ in terms of the fundamental coefficient. It follows that the values of the difference-coefficients obtained by reference to the $\mathrm{AgF}$.P. are nearly the same, and afford a convenient method of reduction at temperatures near $1000^{\circ} \mathrm{C}$. The S.B.P. difference-coefficients do not give very good agreement at $1000^{\circ} \mathrm{C}$. for impure wires.

8. Method of Heycock and Neville.-In the simple and convenient method of reduction enployed by Heycock and Neville, the difference-coefficients for the various pyrometers are calculated as usual from the S.B.P., but the reduction of the observations from $p t$ to $t$ is effected by meaus of a single difference-curve, drawn for the standard wire only, in terms of $p t$ as abscissa. The platinum temperature $p t$ observed with any pyrometer is reduced to the normal scale by taking from the standard curve the difference $t-p t$ corresponding to the observed value of $p t$, and increasing it in the ratio $d / d^{\circ}$ of the appropriate difference-coefficient $d$ to the standard $d^{\circ}$. This method does not give absolute agreement with the difference-formula (2) unless $d=d^{\circ}$, but it often appears to give more consistent results than (2) in the case of impure wires at $1000^{\circ} \mathrm{C}$., and it is simpler to apply, as it requires only one difference-curve, which is drawn for the standard wire. 
The following tables will show how close this agreement is for three of the wires tested. The first column shows, for each case, the temperatures for the standard wire corrected by the difference-formula; the second, headed Test, shows the corresponding values for the impure wire, corrected by Heycock and Neville's method.

TABLE III.

Reduction by Heycock and Nerille's Method.

\begin{tabular}{|c|c|c|c|c|c|}
\hline Standard. & $\begin{array}{c}\text { Test } \\
\text { No. (1). }\end{array}$ & Stanclard. & $\begin{array}{c}\text { Test } \\
\text { No. (2). }\end{array}$ & Standard. & $\begin{array}{c}\text { Test } \\
\text { No. (3). }\end{array}$ \\
\hline $\begin{array}{l}948 \cdot 58 \\
937.90 \\
864.55 \\
8: 9.37 \\
821 \cdot 23 \\
753 \cdot 49 \\
673.38 \\
621 \cdot 79 \\
619 \cdot 67 \\
550.39 \\
549.89 \\
52 \cdot 75 \\
469 \cdot 78\end{array}$ & $\begin{array}{l}948 \cdot 66 \\
9: 38 \cdot 16 \\
864 \cdot 55 \\
839 \cdot 10 \\
821 \cdot 24 \\
753 \cdot 51 \\
673 \cdot 22 \\
6: 21 \cdot 72 \\
619 \cdot 61 \\
550 \cdot 32 \\
549 \cdot 81 \\
52 \cdot 88 \\
469 \cdot 86\end{array}$ & $\begin{array}{l}965 \cdot 9 \\
882 \cdot 8 \\
882 \cdot 3 \\
793 \cdot 9 \\
785 \cdot 7 \\
786 \cdot 1 \\
659 \cdot 5 \\
664 \cdot 6 \\
551 \cdot 4 \\
551 \cdot 8 \\
440 \cdot 0\end{array}$ & $\begin{array}{l}968 \cdot 9 \\
884 \cdot 9 \\
884 \cdot 5 \\
795 \cdot 4 \\
787 \cdot 1 \\
787 \cdot 3 \\
6600 \\
664 \cdot 8 \\
551 \cdot 3 \\
551 \cdot 6 \\
443.7\end{array}$ & $\begin{array}{l}932 \cdot 5 \\
939 \cdot 6 \\
882 \cdot 7 \\
832 \cdot 4 \\
831 \cdot 8 \\
788 \cdot 6 \\
738 \cdot 7 \\
729 \cdot 0 \\
675 \cdot 9 \\
623 \cdot 2 \\
597 \cdot 5 \\
525 \cdot 9 \\
479 \cdot 9 \\
434 \cdot 0\end{array}$ & $\begin{array}{l}932 \cdot 9 \\
939 \cdot 8 \\
882 \cdot 6 \\
832 \cdot 1 \\
831 \cdot 6 \\
788 \cdot 6 \\
738 \cdot 5 \\
728.8 \\
675 \cdot 6 \\
622.9 \\
597 \cdot 3 \\
5256 \\
479 \cdot 7 \\
433 \cdot 9\end{array}$ \\
\hline
\end{tabular}

It will be seen that for the first and third wires the results are in agreement, almost within the limits of error of observation by direct comparison. In the second wire the agreement is not so complete, which is not at all remarkable when it is observed that the temperature-coefficient of this wire is 33 per cent. less than that of the standard. The fourth wire (the most impure) does not agree at all when reduced by this method*.

* Footnote added by Prof. Callendar.-In order to illustrate the nature of the agreement of the observations with the difference-formula and with Heycock and Neville's method, I have inserted in fig. 2 a series of points representing the values of the differences $p t^{\prime}-p t$ for a wire $d=1.650$ calculated by the two methods, $\Theta$ by the difference-formula, $\odot$ by Heycock and Nerille's method. It will be observed that up to $600 \mathrm{pt}$ both methods agree about equally well with the observations. Above $600^{\circ}$ the observed difference is much less than that calculated by the difference-formula. The second method agrees very fairly up to $800^{\circ}$, but tends to diverge from the linear formula bejond that point. 
9. Effect of Annealing.-As before stated, considerable changes of zero were found in some of the wires on tirst heating them to $1000^{\circ}$ for a couple of hours, in one instance a rise of no less than $2^{\circ}$. In this extreme case, there seems to be no reason to doubt that the mica used was largely the cause, as the wire after prolonged use besame slightly discoloured. A specimen of the mica used was tested chemically and found to be slightly acid. The standard wire, which was chemically very pure, was also slightly uffected in this pyrometer; and hence the observations were disregarded. Afterwards some white mica was obtained, from the Instrument Co., Cambridge, and when proper precautions were taken in winding and annealing, the standard wire never showed chinges of zero greater than $0^{\circ} \cdot 2$ or of F.I. greater than $0^{\circ} .03$, after heating to $1000^{\circ} \mathrm{C}$. Most of the impure wires used, however, showed changes somewhat greater than this. In the case of the wire $d=1670$, a fall of $1^{0.2}$ was observed in the zero on first annealing at $1000^{\prime}$ for one hour. This was doubtless due to the fact that, in winding the coil, the wire, as bent on the frame, was in a state of unequal tension, and when beated to $1000^{\circ}$ this was relieved, with a consequent fall of zero on cooling. For accurate work, too great care cannot be exercised in winding the pyrometer-coil. A fall of zero may be easily produced as above, or, if the wire be wound too tight originally, a thickening of the mica may cause a rise of zero, as suggested by Heycock and Neville. After the coil is wound, the pyrometer should be annealed for some time at a temperature beyond that for which it is to be used, and allowed to cool slowly and equally, before the constants are determined. If the pyrometer is used frequently for high temperatures, it is occasionally necessary to redetermine the zero in the most accurate work to allow for minute progressive strains.

10. Effect of Wire-drawing.-In order to test the effect of the mechanical working of the wire on its thermometric scale, I had a piece of wire of diameter 6 mils drawn down to 4 mils, and a double pyrometer made from these two. The wire was softened by passing quickly through a bunsenflame before winding, but not annealed after winding. On VOL. XVII. 
determining the constants, it was found that the platinum temperatures for the boiling-point of sulphur differed by $1^{\circ} 30$. The pyrometer was then heated to $1000^{\circ}$ for an hour, and slowly cooled, and the constants again determined. The wires then agreed at the boiling-point of sulphur to 01 of a degree, and on taking the melting-point of silver a proportionately good agreement was obtained. The difference in the first case was certainly due to insuffoient annealing. The pyrometer was tested again and again, and the results were always in complete agreement. These observations on samples of the same wire led to the conclusion that the constants determined after the high temperatures and not before, as suggested by Heycock and Neville, sbould be used in the calculations (provided that the wire is not strained in cooling), and this has been uniformly done, but the difference in any case is very sligbt.

The wires used differed greatly in specific resistance. In all cases, the wires with the smallest temperature-coefficients had the largest specific resistance, and, with the exception of No. 4, gave the lowest platinum temperatures. The wire $d=1.670$ had a specific resistance about 30 per cent. greater than that of the standard, and the others nearly as great, but the measurements of specific resistance could not be made very accurately on wires of so small a diameter.

In conclusion, I must thank Prof. Callendar for kind assistance, Miss Harriet Brooks, B.A., of the Royal Victoria College, and Mr. N. M. Tuile, M.Sc., of the Mining Department, McGill College, for assistance in taking observations.

McGill College, April 19th, 1900. 